\title{
REMPI mass spectrum of the $\mathrm{OH}$ radical in the gas phase
}

\author{
R. Forster, H. Hippler, K. Hoyermann, G. Rohde \\ Institut für Physikalische Chemie der Universität Göttingen, Tammannstrasse 6, W-3400 Göttingen, Germany
}

and

Lawrence B. Harding

Theoretical Chemistry Group, Chemistry Division, Argonne National Laboratory, Argonne, IL 60439, USA

Received 16 July 1991

\begin{abstract}
The resonance-enhanced multiphoton ionization (REMPI) of the $\mathrm{OH}$ radical in the gas phase was studied using an isothermal discharge-flow reactor for the production of $\mathrm{OH}$ radicals $\left(\mathrm{H}+\mathrm{NO}_{2} \rightarrow \mathrm{OH}+\mathrm{NO}\right)$, tunable laser light from an excimer-pumped dye laser, and a time-of-flight (TOF) mass spectrometer. A mass-resolved REMPI spectrum was found in the wavelength region of $290-310 \mathrm{~nm}$, which is assigned to a $(3+1)$ ionization process. An ab initio quantum-chemical calculation predicts the Rydberg state, verified by the experiment.
\end{abstract}

\section{Introduction}

The $\mathrm{OH}$ radical in the gas phase plays a central role in many reactive systems of basic and technical interest like hydrocarbon oxidation and air chemistry. The detection by spectroscopic methods and the analysis of the spectra involving low-lying energetic states are well developed. Besides the identification by absorption, emission and resonance-absorption spectroscopy, an increasing application of laser-based methods is to be noticed: laser-induced fluorescence (LIF) [1], laser-induced saturation fluorescence [2], laser-induced predissociation fluorescence (LIPF) [3], laser magnetic-resonance spectroscopy (LMR) [4], and resonance-enhanced multiphoton ionization/photoelectron spectroscopy (REMPI-PES) [5]. (The few references are chosen for a basic description and a recent application and do not reflect the priority; for a review, see also ref. [6].) Here we report on the multiphoton ionization of the $\mathrm{OH}$ radical and the detection by mass spectroscopy (REMPIMS). The REMPI method can be a useful addition to the methods available as it is very sensitive via single-ion detection and as it might be specific if there exists a radical specific wavelength for ionization, a low spectral interference with other species present and an ion-mass selection. A high sensitivity for the detection of radicals is often observed via the ionization of a Rydberg state [7]. The increasing capabilities of precise ab initio quantum-chemical calculations and the prediction of energetically highlying electronic states (as Rydberg states of the $\mathrm{OH}$ radicals) encouraged this joint project of the theoretical prediction and the experimental verification, whose result is presented in this Letter.

\section{Experimental}

The experimental arrangement as shown in fig. 1 has been described partly in a previous paper [8]. It is a combination of an isothermal discharge-flow reactor coupled to the ion source of a TOF mass spectrometer for a laser-induced multiphoton ionization and a mass-selective ion detection by a timed transient digitizer and/or a boxcar integrator. The $\mathrm{OH}$ radicals are produced in the isothermal flow reactor by the reaction $\mathrm{H}+\mathrm{NO}_{2} \rightarrow \mathrm{NO}+\mathrm{OH}$, where the $\mathrm{H}$ atoms are formed by the microwave discharge of highly diluted $\mathrm{H}_{2} / \mathrm{He}$ mixtures and the $\mathrm{NO}_{2}$ (diluted with 


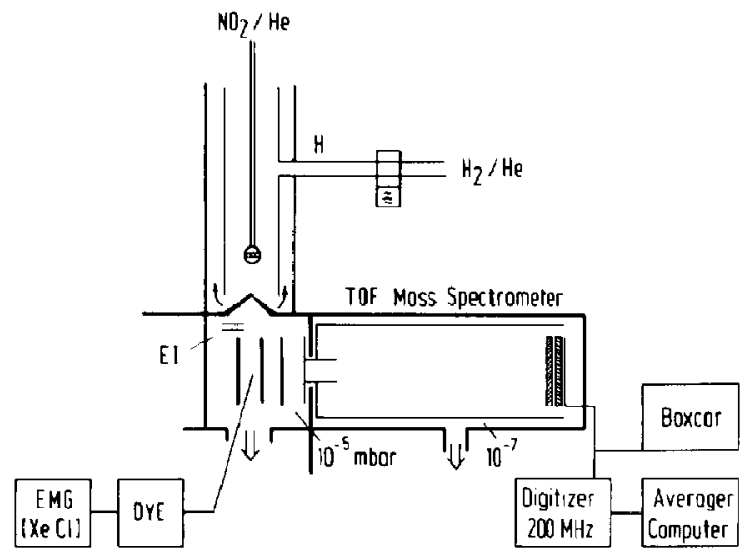

Fig. 1. Experimental arrangement.

$\mathrm{He} / \mathrm{Ar}$ ) is admixed into the main flow by a movable inlet probe. Typical experimental conditions for the $\mathrm{OH}$ source are: pressure in the flow reactor around $1 \mathrm{mbar}$, linear flow velocity around $30 \mathrm{~m} / \mathrm{s}$, mole fraction of $\mathrm{OH}<0.3 \mathrm{~mol} \%$ (i.e. $[\mathrm{OH}]=1.4 \times 10^{-10}$ $\mathrm{mol} / \mathrm{cm}^{3}, 7 \times 10^{13}$ molecule $\left./ \mathrm{cm}^{3}\right)$, temperature around $295 \mathrm{~K}$.

By the expansion through a conical nozzle the $\mathrm{OH}$ radicals pass the ion source of the mass spectrometer (surrounding pressure $10^{-5}-10^{-6} \mathrm{mbar}$ ). Multiphoton ionization is achieved by focusing the laser light into the center of the ion source. An excimer laser (Lambda Physik LPX 205 iCC; XeCl) pumps the dye laser (Lambda Physik FL 2002) for the SHG (KDP, FL 30) of laser light in the region 290-312 nm. (Dye: rhodamin 6G, rhodamin B.) The $\mathrm{OH}^{+}$ ions are extracted in several stages and injected into the drift tube for the detcetion by a doublc-stage microchannel plate detector. The mass spectrum is either recorded by a transient digitizer and averaged over 50-500 cycles (LeCroy SA 3500) or by a gated boxcar integrator/averager (SRS), the latter especially for the measurements of the wavelength dependence of the $\mathrm{OH}^{+}$ion production (see fig. 3 ).

\section{Results and discussion}

\subsection{Theoretical predictions}

The theoretical study consists of multi-reference, singles and doubles, configuration-interaction cal- culations. The calculations employ a polarized valence double-zeta basis set [9] augmented with two sets of diffuse s functions ( $\alpha=0.064$ and 0.024$)$ and two sets of diffuse $\rho$ functions ( $\alpha=0.052$ and 0.017 ) on the oxygen atom. The diffuse functions were optimized to describe the $3 \mathrm{~s}$ and $3 p$ Rydberg states of atomic oxygen. For the ground state of the neutral and the positive ion, the reference wavefunctions consist of a full-valence complete active space (CAS) ( 6 or 7 clectrons and 5 orbitals), with the orbitals self-consistently optimized for each of these states. The Rydberg states were obtained from CI calculations employing the orbitals from the positive ion. For these states, the active orbitals include the five valence orbitals from the ion together with the two lowest sigma virtuals ( $3 \mathrm{~s}$ and $3 \mathrm{p}_{z}$ ) and the lowest $\pi$ virtuals $\left(3 \mathrm{p}_{x}\right.$ and $\left.3 \mathrm{p}_{y}\right)$. The reference wavefunction then consists of a CAS amongst these active orbitals with the restriction that only one electron is allowed into the four Rydberg functions. The calculations were carried out with the COLUMBUS program package [10] on a Cray-XMP computer. The calculated excitation energies are summarized in table 1 .

The calculated ionization potential is too low by approximately $0.5 \mathrm{eV}$ due to the use of a relatively small basis set. It is expected that the errors in the Rydberg excitation energies should be quite similar to that in the ionization potential. These predictions are shown in parentheses in table 1. The good agreement between the calculated and observed excitation energies for the $D$ state validates the theoretical model used here.

The state of most interest in the present context is the $3^{2} \Pi$ state. The present calculations agree with earlier predictions [12] that this state exhibits a sharp avoided crossing with the $2^{2} \Pi$ state as the character of the state changes from $\left(\pi \rightarrow 3 p_{\pi}\right)$ to $(\sigma \rightarrow 3 s)$. This crossing occurs very close to the minimum of the $3^{2} \Pi$ state. The calculated potential curves are given in fig. 2 .

\subsection{Measurements}

\subsubsection{Mass spectrum}

In fig. 3a, the mass spectrum of the $\mathrm{OH}$ radical at the wavelength $293.2 \mathrm{~nm}$ is shown. At this wavelength, an additional fragment ion $\left(\mathrm{O}^{+}\right)$at $m / e=16$ 
Table 1

Calculated and experimental excitation energies (eV) of OH. For the Rydberg states, the numbers in parentheses are obtained by combining the calculated binding energy of the state relative to the ${ }^{3} \Sigma^{-}$ion and the observed ionization potential

\begin{tabular}{|c|c|c|c|c|}
\hline State & Character & $\begin{array}{l}\text { Vertical excitation } \\
\text { energy }\end{array}$ & $\begin{array}{l}\text { Adiabatic excitation } \\
\text { energy }\left(T_{e}\right)\end{array}$ & $\begin{array}{l}\text { Exp. } \\
\left(T_{c}\right)\end{array}$ \\
\hline $1^{2} \Sigma^{+}$(A state) & $(\sigma \rightarrow \pi)$ & 4.27 & 4.24 & 4.05 \\
\hline $2^{2} \Sigma^{+}$(B state) & $(\pi \rightarrow 3 s)$ & $11.26(11.8)$ & b) & 8.65 \\
\hline $1^{2} \Sigma^{-}$ & $(\pi \rightarrow 3 s)$ & $7.87(8.4)$ & - & \\
\hline $2^{2} \Sigma^{-}$(D state) & $\left(\pi \rightarrow 3 p_{z}\right)$ & $9.90(10.4)$ & $9.82(10.3)$ & 10.18 \\
\hline $1^{2} \Delta$ & $(\pi \rightarrow 3 s)$ & $9.86(10.4)$ & - & \\
\hline $2^{2} \Pi$ & $\left(\pi \rightarrow 3 p_{\pi}\right)$ & $10.01(10.5)$ & $9.94(10.4)$ & \\
\hline $3^{2} \Pi$ & $\left(\pi \rightarrow 3 p_{\pi}\right)$ and $(\sigma \rightarrow 3 s)$ & $12.08(12.6)$ & $10.49(11.0)$ & \\
\hline $1^{3} \Sigma^{-}$(ion) & $(\pi \rightarrow \infty)$ & 12.49 & 12.43 & $12.9-13.0$ \\
\hline
\end{tabular}

a) Ref. [11].

b) The B state should have a long-range minimum which was not examined in this study.

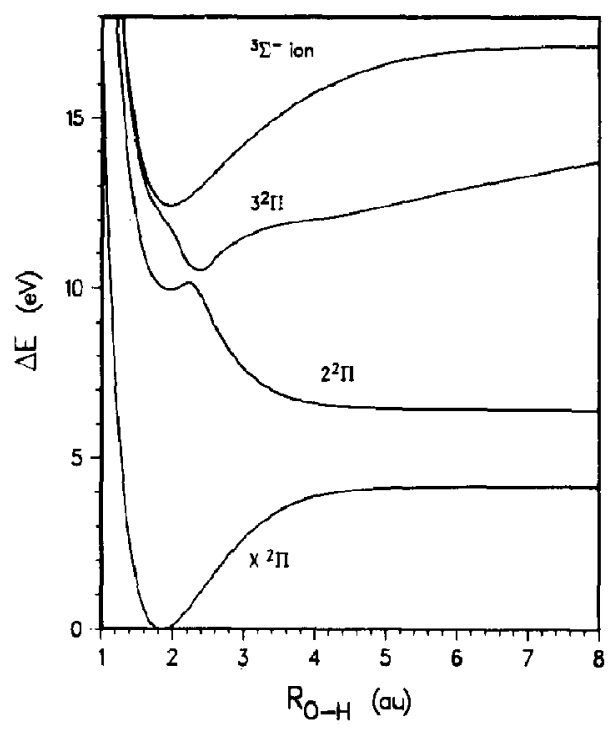

Fig. 2. Potential curves of the $\mathrm{OH}$ radical. (For the assignment of the states see table 1.)

is observed, whose intensity is lower at other wavelengths. (The signal at $m / e=12$ is due to residual hydrocarbons present despite the use of turbo-molecular pumps in the experimental setup. The signal at $m / e=15$ at this wavelength is due to an unidentified impurity produced by the microwave discharge, present, too, in the absence of reactants $\mathrm{H}$ / $\mathrm{H}_{2} / \mathrm{NO}_{2} / \mathrm{NO}$.) The wavelength-specific detection of $\mathrm{OH}$ radicals is obvious by comparing the mass spectra in figs. $3 a$ and $3 b$, where in fig. $3 b$ no multiphoton ionization of $\mathrm{H}_{2} \mathrm{O}$ is observed. (Under the con-

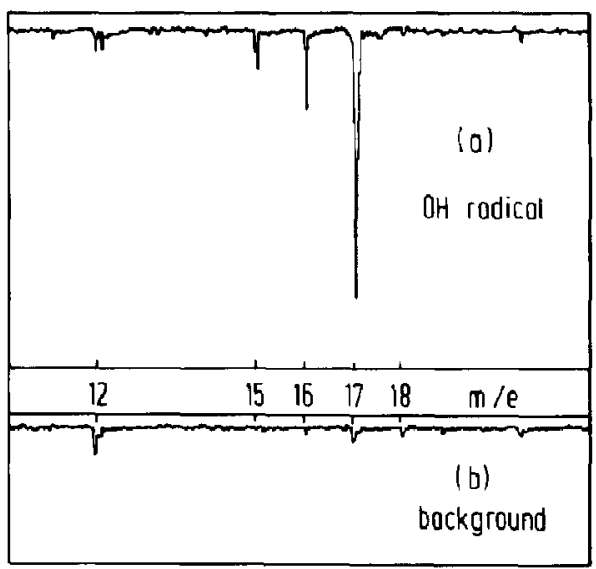

Fig. 3. REMPI mass spectrum of the $\mathrm{OH}$ radical at a wavelength of $293.2 \mathrm{~nm}$ : (a) $\mathrm{OH}$ radical as produced by the reaction $\mathrm{H}+\mathrm{NO}_{2} \rightarrow \mathrm{OH}+\mathrm{NO}$; (b) background (absence of the $\mathrm{OH}$ radical, discharge for the production of $\mathrm{H}$ atoms off, $\mathrm{H}_{2} \mathrm{O}$ added).

ditions of fig. $3 b$, microwave discharge off, only $\mathrm{He} /$ $\mathrm{H}_{2} / \mathrm{NO}_{2}$ and added $\mathrm{H}_{2} \mathrm{O}$ are present.)

\subsubsection{Wavelength dependence: spectrum of the $\mathrm{OH}$ radicals}

The multiphoton ionization spectrum of the $\mathrm{OH}$ radicals was observed in the wavelength region $290.0-310.0 \mathrm{~nm}$ as shown.in figs. $4 \mathrm{a}-4 \mathrm{~d}$. The calibration of the wavelength scale was performed by comparison with the lines of a Ne lamp. Typical laser repetition rates were $5-10 \mathrm{~Hz}$ at an average pulse energy of $2 \mathrm{~mJ}$ and a spectral resolution of $0.198 \mathrm{~cm}^{-1}$. The gate time of the boxcar averager was $70 \mu \mathrm{s}$ with 
J.A. Silver, W.L. Dimpfl, J.H. Brophy and J.L. Kinsey, J. Chem. Phys. 65 (1976) 1811;

J.E. Goldsmith, Appl. Opt. 29 (1990) 4841.

[2] K. Kohse-Höinghaus, R. Heidenreich and T. Just, 20th Symposium (International) on Combustion (The Combustion Institute, Pittsburgh, 1984) p. 1177.

[3] P. Andresen, A. Barth, W. Groger, H.W. Lulf, G. Meijer and J.J. terMeulen, Appl. Opt. 27 (1988) 365.

[4] K.M. Evenson, J.S. Wells and H.E. Radford, Phys. Rev. Letters 25 (1970) 199;

P.B. Davies, W. Hack, A.W. Preuss and F. Temps, Chem. Phys. Letters 64 (1979) 94.

[5] E, de Beer, M.P. Koopmans, C.A de Lange, W.A. Chupka and $Y$. Wang, private communication (September 1990).

[6] A.C. Eckbreth, 18th Symposium (International) on Combustion (The Combustion Institute, Pittsburgh, 1981) p. 147!;

W. Hack, Intern. Rev. Phys. Chem. 4 (1985) 165.

[7] J.W. Hudgens, in: Advances in multi-photon processes and spectroscopy, ed. S.H. Lin (World Scientific, Singapore, 1987).
[8] P. Heinemann-Fiedler and K. Hoyermann, Ber. Bunsenges. Physik, Chem. 92 (1988) 1472.

[9] T.H. Dunning Jr., J. Chem. Phys. 90 (1989) 1007.

[10] R. Shepard, I. Shavitt, R.M. Pitzer, D.C. Comeau, M. Pepper, H. Lischka, P.G. Szalay, R. Ahlrichs, F.B. Brown and J.-G. Zhao, Intern. J. Quantum Chem. Symp. 22 (1988) 149.

[11] K.P. Huber and G. Herzberg, Molecular spectra and molecular structure, Vol. 4. Constants of diatomic molecules (Van Nostrand Reinhold, New York, 1979) p. 508.

[12] E.F. van Dishoeck and A. Dalgarno, J. Chem. Phys. 79 (1983) 873 .

[13] R.W.B. Pearse and A.G, Gaydon, The identification of moleculear spectra, 4th Ed. (Chapman and Hall, London, 1976) p. 264.

[14] S.G. Lias, J.E. Bartmess, J.F. Liebman, J.L. Holmes, Rh.D. Levin and W.G. Mallard, J. Phys. Chem. Ref. Data 17, Suppl. 1 (1988).

[15] J.A. Stephens and V. McKoy, Phys. Rev. Letters 62 (1989) 889 